Portland State University

PDXScholar

\title{
Investigating Mentor Commitment In Youth Mentoring Relationships: The Role of Perceived Program Practices
}

\author{
Alison L. Drew \\ Boston University \\ Thomas E. Keller \\ Portland State University, kellert@pdx.edu \\ Renee Spencer \\ Boston University \\ Carla Herrera \\ Portland State University
}

Follow this and additional works at: https://pdxscholar.library.pdx.edu/socwork_fac

Part of the Social Work Commons

Let us know how access to this document benefits you.

\section{Citation Details}

Published as: Drew, AL, Keller, TE, Spencer, R, Herrera, C. Investigating mentor commitment in youth mentoring relationships: The role of perceived program practices. J Community Psychol. 2020; 48: 2264: 2261- 2276. https://doi.org/10.1002/jcop.22409

This Post-Print is brought to you for free and open access. It has been accepted for inclusion in Social Work Faculty Publications and Presentations by an authorized administrator of PDXScholar. Please contact us if we can make this document more accessible: pdxscholar@pdx.edu. 
Investigating mentor commitment in youth mentoring relationships:

The role of perceived program practices

\author{
Alison L. Drew ${ }^{1}$ \\ Thomas E. Keller ${ }^{2}$ \\ Renée Spencer ${ }^{1}$ \\ Carla Herrera ${ }^{3}$ \\ ${ }^{1}$ Boston University \\ ${ }^{2}$ Portland State University \\ ${ }^{3}$ Independent Researcher
}

This study was supported by funding to the second author from the William T. Grant Foundation (Grant \#182183). The opinions, findings, and conclusions or recommendations expressed in this publication are those of the authors and do not necessarily reflect those of the sponsor. This project was undertaken in collaboration with MENTOR: The National Mentoring Partnership, several of its affiliates, and many youth mentoring programs.

TK, RS \& CH serve on the Research Board of MENTOR's National Mentoring Resource Center. All authors have consulted with MENTOR regarding updates and improvements to the QMS intervention. Correspondence for this article should be addressed to Alison L. Drew, Boston University School of Social Work, 264 Bay State Road, Boston, MA 02215 or adrew@bu.edu.

This is an author preprint version of an article that should be cited as:

Drew, A.L., Keller, T.E., Spencer, R., \& Herrera, C. (2020). Investigating mentor commitment in youth mentoring relationships: The role of perceived program practices. Journal of Community Psychology, 48, 2264-2276. DOI: 10.1002/jcop.22409 
PROGRAM PRACTICES AND MENTOR COMMITMENT

\section{Abstract}

Aims: Highly committed mentors may be less likely to end their mentoring relationships with their mentees. Theory suggests commitment is predicted by relationship satisfaction, investment, and perceptions of available alternatives. Mentoring program practices may influence commitment, but little research has investigated potential mechanisms.

Methods: Using data from 537 mentors representing 55 mentoring programs, this study examined a theoretical path model in which mentor perceptions of program practices, specifically setting expectations, pre-match mentor training, and matching based on mentor preferences, predict mentor satisfaction, investment, perceptions of available alternatives, and ultimately, relationship commitment.

Results: As expected, commitment was associated positively with satisfaction and investment and negatively with available alternatives. Perceptions of the program setting clear expectations, the amount of pre-match training, and matching by preferences predicted mentor commitment. These associations were mediated by relationship satisfaction, investment, and available alternatives, respectively.

Conclusion: These findings identify program practices that can support mentor commitment. Keywords: youth mentoring, relationship commitment, Investment Model, program practices 
PROGRAM PRACTICES AND MENTOR COMMITMENT

Investigating mentor commitment in youth mentoring relationships:

The role of perceived program practices

Many formal mentoring programs ask mentors to form long-term relationships with

youth, typically for at least one school year or a calendar year, with the intent to provide positive developmental opportunities for the young person. The impact of the relationship depends, in part, on how long the mentor continues the relationship (e.g., Grossman \& Rhodes, 2002;

Herrera, Grossman, Kauh, Feldman, McMaken \& Jucovy, 2007), which may be influenced by the mentor's commitment to the relationship (Gettings \& Wilson, 2014). In many ways, the context for a successful mentoring relationship is set by the mentoring program (Keller, 2005a). The mentoring program is responsible for preparing the mentor, matching the mentor with an appropriate youth, and setting guidelines for the match (MENTOR, 2015). While evidence suggests that program practices are associated with relationship longevity and youth outcomes (DuBois, Holloway, Valentine \& Cooper, 2002; DuBois, Portillo, Rhodes, Silverthorn \& Valentine, 2011; Kupersmidt, Stump, Stelter \& Rhodes, 2017), little research has focused on the mechanisms by which specific program practices may influence mentor commitment. The current theory-driven study empirically examines the correspondence between mentors' perceptions of program practices and mentors' commitment to their mentoring relationships.

\section{Relationship Commitment}

Theory and empirical evidence suggest that the benefits of youth mentoring, in areas such as increased academic engagement, reduced risk-taking, and improved family and peer relationships (e.g., Deutsch, Reitz-Krueger, Henneberger, Futch Ehrlich \& Lawrence, 2017;

Grossman \& Rhodes, 2002; Grossman \& Tierney, 1998; Herrera, DuBois \& Grossman, 2013; Herrera, Grossman, Kauh \& McMaken, 2011; Parra, DuBois, Neville, Pugh-Lily \& Povinelli, 
PROGRAM PRACTICES AND MENTOR COMMITMENT

2002; Wheeler, Keller \& DuBois, 2010), are achieved within the context of a strong, consistent relationship with a supportive mentor over time (Karcher, 2005; Parra et al., 2002; Rhodes, 2002, 2005; Rhodes, Spencer, Keller, Liang \& Noam, 2006; Spencer, 2007a). Commitment, which reflects a person's intention to sustain and remain psychologically attached to a relationship (Rusbult, 1980; Rusbult, Martz \& Agnew, 1998), provides an important indicator of the likelihood that someone will choose to continue or terminate a relationship across a wide variety of interpersonal relationships (e.g., Le \& Agnew, 2003; Rusbult, 1980; Rusbult \& Martz, 1995; Rusbult et al., 1998; Tran, Judge \& Kashima, 2019). According to Rusbult's (1980) investment model, commitment to the relationship is predicted by satisfaction with the relationship (i.e., weighing the costs and benefits of the relationship and comparisons to past relationship experiences and expectations for an ideal relationship), investment (the magnitude and importance of what has been put into the relationship that would be lost or lose value if the relationship were to end, including both intrinsic and extrinsic investments) and available alternatives (i.e., the availability and desirability of other potential mentees or not having a mentoring relationship). As was found with other interpersonal relationships, initial research suggests that satisfaction and investment are positively associated with the mentor's commitment to the youth, while the perception of available alternatives has a negative association (Gettings \& Wilson, 2014).

\section{The Importance of Program Practices}

The mentor's commitment to the mentoring relationship does not develop in a vacuum, free from outside influence. The mentor's satisfaction, investment, available alternatives, and corresponding commitment are likely affected by the mentoring program's practices. Even before the mentor meets with the mentee, the mentoring program may implement practices that 
PROGRAM PRACTICES AND MENTOR COMMITMENT

influence the mentor's experiences in the match through marketing messages, training, and guidelines regarding the purpose and expectations for the match (Keller, 2005b). While there are many ways the mentoring program may do this, three evidence-supported program practices (MENTOR, 2015) that may be related to satisfaction, investment, and perceptions of available alternatives are: 1) setting clear expectations for the match; 2) providing mentors with pre-match training; and 3) considering mentors' preferences in selecting a mentee.

It is important for mentoring programs to set realistic expectations with mentors when they explain the program's purpose and the role of a mentor during the screening and training processes (MENTOR, 2015). Qualitative research has shown that one reason mentors leave their relationships is because they are disappointed when their expectations are unmet (Spencer, 2007b; Spencer, Basualdo-Delmonico, Walsh \& Drew, 2017; Spencer, Gowdy, Drew, McCormack \& Keller, 2019). Because satisfaction with a relationship is based on comparing it to expectations for an ideal relationship and understanding the potential benefits of the match (Rusbult, 1980), it is likely that mentors who feel that expectations were clearly and appropriately set by the program will feel more satisfied with their match and therefore will be more committed.

It is recommended that mentoring programs provide at least two hours of in-person, prematch training for all new mentors (MENTOR, 2015). Research has demonstrated that mentors who receive training are more likely to meet their minimum time commitment (Herrera et al., 2013) and generally have longer matches (Kupersmidt et al., 2017). Additionally, the amount of pre-match training also may make an important contribution to mentor retention (McClanahan, 1998; Herrera et al., 2007), which is likely indicative of a committed mentor. Devoting time and effort to preparing for the mentoring experience, including participation in pre-match training, 
PROGRAM PRACTICES AND MENTOR COMMITMENT

represents one form of mentor investment that may translate to increased commitment to the mentoring relationship. Further, pre-match training may contribute to mentors' investment indirectly by influencing other mentor behaviors that lead to a sense of investment and commitment. For example, Herrera and colleagues (Herrera, Sipe \& McClanahan, 2000) found that mentors who reported receiving more pre-match training also tended to report spending more time with their mentees and to engage in more social activities with them, both of which are forms of investment that may result in greater commitment.

A third recommended program practice is considering the mentor's preferences when matching a mentor with a youth (MENTOR, 2015). Programs that match mentors with youth based on preference show larger effect sizes (DuBois et al., 2011). There are several theoretical reasons why matching based on preferences may improve match outcomes (e.g., similarityattraction paradigm, voice and choice; Pryce, Kelly \& Guidone, 2014). Another potential explanation is that mentors who feel the program matched them with a youth based on their preferences will be less likely to think they could better serve a different youth (i.e., there are not better alternatives to their current relationship), which should increase relationship commitment (Rusbult, 1980).

\section{Hypotheses}

Despite growing evidence of the program's role in fostering successful matches, there has been little attention in the literature to how mentor's perceptions of program practices specifically influence mentor commitment. Applying Rusbult's investment model (1980) to youth mentoring relationships, it is hypothesized that satisfaction with and investment in the mentoring relationship will be positively correlated with mentor commitment, and available alternatives will be negatively correlated with commitment (Figure 1). In addition, commitment 
PROGRAM PRACTICES AND MENTOR COMMITMENT

is expected to be predicted by the mentor's perception of the extent to which the program set realistic expectations prior to the match, the amount of pre-match mentor training provided, and the extent to which the mentor felt the program considered their preferences in the match-making process. The associations between these perceptions of program practices and relationship commitment are hypothesized to be mediated by investment model variables. Specifically, the mentor's perception of the program setting realistic expectations prior to the match will be mediated by satisfaction in the relationship; how much pre-match training the mentor had will be mediated by level of investment; and the extent to which the mentor feels that preferences were considered during the matching process will be mediated by perceptions of available alternatives.

\section{Method}

To examine the association between mentors' perceptions of program practices and mentor commitment, this study utilized data from a large, multi-state, randomized controlled trial (RCT) evaluating implementation of the Quality Mentoring System (QMS) (Keller, Spencer, Herrera \& McBeath, 2018). QMS is an initiative of MENTOR: The National Mentoring Partnership, in which its state-level affiliates implement a quality rating and improvement strategy with mentoring programs to strengthen their organizational functioning and program service delivery. The RCT randomized at the program level. Prior to randomization and QMS intervention, survey data were collected from three types of respondents: an agency leader; all mentoring program staff; and a random sample drawn from all active mentors within the program. To determine program-level changes associated with the QMS intervention, additional surveys were collected approximately 15 months later from separate but comparable samples drawn from the programs at that time: an agency leader; all current mentoring program staff; and 
PROGRAM PRACTICES AND MENTOR COMMITMENT

a second random sample of active mentors. The current study examines cross-sectional data from mentor surveys at the first assessment, prior to program randomization.

\section{Procedures}

MENTOR identified eight state-level affiliates to participate in the QMS trial. Each affiliate was responsible for recruiting mentoring programs from within their networks to implement QMS. The number of programs recruited by each affiliate varied based on its capacity to support programs through the intervention. Affiliates were encouraged to target programs reflecting the diversity of mentoring programs in their area with attention to factors such as program structure, model, setting and size. As noted, prior to program randomization, there was an attempt to collect surveys from a random sample of 15 mentors from each program, or all program mentors if fewer than 15 were active at the time. Program staff produced a numbered list of all eligible mentors in their program, providing the researchers with the total number and no identifying information. Researchers then generated a random sequence of 20 numbers to indicate the mentors to be sampled. The first 15 mentors were contacted by mentoring program staff who described the study and sought permission from the mentor to release contact information to the research team. If any mentor was not willing or could not be reached, the next prospective participant on the list was contacted until 15 mentors had given permission. Interested mentors were sent an introductory email with information about the study and a link to the online study consent form and survey. Participants were offered a $\$ 20$ gift card as an honorarium. All data were collected online using Qualtrics. Recruitment and data collection followed IRB-approved procedures.

\section{Participants}


PROGRAM PRACTICES AND MENTOR COMMITMENT

The current analysis is based on survey data from mentors in 55 programs recruited by six of the state-level affiliates (see Table 1 for a summary of program characteristics). A total of 593 mentors from these mentoring programs consented to the initial survey. The number of mentors from each program ranged from 1 to $15(M=10.0, S D=3.33)$. To be included in the final analysis, each participant needed to have valid data for the commitment variable and each of the demographic variables. Due to missing data, 56 participants were excluded from the analysis, resulting in 537 participants being included in the final sample.

Participants (66.9\% female) ranged in age from 18 to 80 years old $(M=39.21, S D=$ 15.68). The majority of participants identified as European American/White (69.1\%), with 20.9\% African American/Black, 6.2\% Asian American/Asian, 1.1\% American Indian/Alaska Native, $0.7 \%$ Native Hawaiian or Other Pacific Island, and 3.4\% Other (participants could choose all racial backgrounds that apply). A small proportion of participants (4.1\%) identified as being Hispanic or Latino. Nearly half of the mentors (47.4\%) reported being currently married, and $35.4 \%$ had children of their own. Most mentors had completed at least a bachelor's degree (73.2\%) and reported a household income above $\$ 60,000$ (61.0\%). A sizeable proportion (43.2\%) reported volunteering with another organization in addition to the mentoring program. Participants served as mentors in programs representing a wide range of mentoring models. Most participants were in one-to-one mentoring relationships (88.3\%), meaning that even if the mentor had multiple mentees, they met with each one individually. The remaining mentors were in group (one mentor with a group of mentees), team (a team of mentors working with a group of mentees), or multiple mentoring (multiple mentors working with one mentee) formats. While most mentors were assigned to just one mentee (78.6\%), others reported being assigned up to 60 mentees at the time of data collection. Mentors served in a variety of settings, 
PROGRAM PRACTICES AND MENTOR COMMITMENT

with $53.4 \%$ in site-based programs, $34.8 \%$ in community-based programs, and $11.8 \%$ in other settings (e.g., online mentoring, hybrid). Almost all mentors were volunteers (96.6\%); however, a small number (18) were hired and paid to serve as mentors.

\section{Measures}

Mentors matched with multiple youth were instructed to "respond to all questions on this survey thinking of the mentee to whom you have been matched for the longest time. If you began mentoring multiple mentees at the same time, please think about the mentee whose name comes first alphabetically."

\section{Mentoring Relationship.}

Commitment. Commitment to the mentoring relationship was measured using an adapted version of the Investment Model Scale (Rusbult et al., 1998), which was originally developed for application to romantic relationships and has been successfully used in a variety of settings (Le \& Agnew, 2003; Tran et al., 2019) including a recent adaptation for adults mentoring youth (Gettings \& Wilson, 2014). Commitment was measured using 4 items (e.g., "I am determined to make my relationship with my mentee successful'") rated on a 5-point scale (1= Strongly Disagree to 5= Strongly Agree). The adapted commitment scale had acceptable reliability among mentors in this sample $(\alpha=.83)$.

Predictors of Commitment. According to Rusbult's (1980) model, commitment to the relationship is predicted by satisfaction, investment and available alternatives. Satisfaction, investment and available alternatives were measured using an adapted version of the Investment Model Scale (Rusbult et al., 1998). Satisfaction was measured using 5 items (e.g., "My relationship with my mentee is an important source of fun and companionship in my life"), investment using 5 items (e.g., "I have invested a great deal of time in my relationship with my 
PROGRAM PRACTICES AND MENTOR COMMITMENT

mentee"), and available alternatives using 4 items (e.g., "I think my experience as a mentor probably would be better with a different mentee"). All items were rated on a 5-point scale (1= Strongly Disagree to 5= Strongly Agree). Reliabilities for the scales were acceptable (Satisfaction: $\alpha=.85$, Investment: $\alpha=.73$, Alternatives: $\alpha=.89$ ).

\section{Mentor Perceptions of Program Practices.}

Expectation setting. Mentor perceptions of how realistically their program set expectations for the mentoring experience prior to the match was measured using 3 items rated on a 5-point scale $(1=$ Not at all true to $5=$ Very true $)$. Participants were asked to what extent the mentoring program realistically portrayed the benefits and challenges of being a mentor in the program, provided them with an accurate view of the roles and expectations of mentors in the program, and oriented them to the mission, goals, and intended outcomes of the program $(\alpha=$ $.85)$.

Pre-match training. How much training mentors completed before being matched was measured with a single question. Mentors indicated how much group training they had received prior to matching on a 6 -point scale $(1=$ None, $2=$ Less than 30 minutes, $3=30$ minutes to less than 1 hour, $4=1$ hour to less than 2 hours, $5=2$ hours to less than 4 hours, $6=4$ hours or more).

Matching. Mentors were asked whether they felt the program "matched you to a mentee in a way that accounted for personal characteristics, goals, and preferences." Mentors indicated their perception using a 5 -point scale $(1=$ Not at all true, $5=$ Very true $)$.

\section{Control Variables.}

Demographic characteristics of mentors and youth. Mentors were asked to report their gender, age, and race/ethnicity as well as that of their mentee. A dichotomous variable was created for race/ethnicity, coded 1 for "White, non-Hispanic" and 0 for all others. 
PROGRAM PRACTICES AND MENTOR COMMITMENT

Mentoring context. Because the mentoring relationships included in this dataset represent a wide variety of mentoring programs and models, three measures of mentoring context, reported by the mentor, were included as control variables in analyses. All of these contextual variables were dichotomous. Mentors reported the capacity in which they mentored (volunteer or paid staff), the primary format of the mentoring (one-on-one or other) and the setting (community-based or other).

\section{Analysis}

The initial step in the analysis was to examine bivariate correlations among all variables included in the model to observe whether associations were in the hypothesized direction. Next, a series of structural models were tested with MPlus, version 8, using full information maximum likelihood. Multilevel modeling was used to account for the nesting of participants within programs. Multilevel modeling was necessary given between-program variation in model variables, in particular the mentor-reported program practices, as indicated by intraclass correlations (see Table 2). For parsimony, control variables not significantly associated with model variables were removed from path models. First, the associations between satisfaction, investment, available alternatives and commitment predicted in the Investment Model (Rusbult, 1980) were tested to confirm that they held in this dataset. The next set of models examined the hypothesized mediation of each program practice through its corresponding component of the Investment Model on mentor commitment (e.g., Setting expectations > Satisfaction > Commitment). Finally, incorporating each of these component models, the full hypothesized path model presented in Figure 1 was evaluated. Path analysis allows for the testing of a theorydriven model demonstrating the relationships between multiple exogenous variables and endogenous variables as hypothesized (Garson, 2014; Hancock \& Mueller, 2004). Given the 
PROGRAM PRACTICES AND MENTOR COMMITMENT

sample size, indices other than the chi-square test were used to assess model fit (Garson, 2014).

Comparative fit index (CFI) values above .95 are considered good model fit. A root mean square error of approximation (RMSEA) value $<.05$ is considered a good model fit, and a value $<.08$ is considered adequate. The $\mathrm{R}^{2}$ values are reported for all endogenous variables.

\section{Results}

Correlations and descriptive statistics for all model variables are presented in Table 2.

The amount of time the mentor spent in pre-match training was not significantly associated with the mentor's perceptions of available alternatives. All other correlations between model variables were statistically significant and in the direction proposed in the hypotheses. Table 2 also shows that the intraclass correlations (ICCs) for the Investment Model variables ranged from .042 to .095 . In addition, as anticipated, the ICCs for program practices were substantial (.159 to .316 ), indicating high within-program agreement and between-program differences.

The analysis indicated that these data support the paths hypothesized by the Investment Model (Table 3). As predicted, mentor relationship commitment was positively associated with relationship satisfaction and investment, and negatively associated with available alternatives. In addition, the initial model for mentors' perception of how well the program set expectations (labeled Model A) established that this practice had a statistically significant, direct association with commitment, consistent with the bivariate correlation. The second model for mentors' perception of expectation setting (labeled Model B) indicated the association with commitment was fully mediated by the corresponding Investment Model variable, satisfaction. Specifically, the direct path between mentors' perceptions of the program practice and commitment approached zero and was no longer statistically significant when the mediating Investment Model variable was included. In addition, the model fit indices suggested that Model B was a 
PROGRAM PRACTICES AND MENTOR COMMITMENT

stronger fit for the data than Model A. Parallel analyses yielded the same pattern of results for the other hypothesized connections between perceived practices and mentor commitment.

Specifically, pre-match training was associated with commitment, and this association was fully mediated by investment. Likewise, perceptions of matching based on preferences was associated with commitment, and this association was fully mediated by available alternatives. Based on these findings, the full hypothesized path model was analyzed predicting full mediation of all program practices as shown in Figure 1.

All paths in the final hypothesized path model (Figure 2) were statistically significant in the direction predicted. Overall, the model had goodness-of-fit indices indicating adequate fit of this theoretically driven model. With respect to mediating mechanisms, the results suggest that the association between mentors' perceptions of the agency setting expectations and mentor commitment was mediated by the mentor's satisfaction with the relationship. Similarly, the amount of time the mentor spent in pre-match training was positively associated with mentor investment, which was in turn associated with commitment. Finally, as expected, mentors feeling that they were matched to a youth based on their preferences was negatively associated with perceptions of available alternatives, meaning mentors were more likely to be pleased with their actual mentee, and the available alternatives variable mediated the relationship between matching and commitment.

\section{Discussion}

The results of our theory-driven analyses, conducted using data from mentors representing a wide array of mentoring programs, support the hypothesis that mentors' perceptions and experiences of program practices are associated with mentor commitment. Of note, this study is among the first to focus on the mechanisms by which specific program 
PROGRAM PRACTICES AND MENTOR COMMITMENT

practices may influence mentor commitment. Given the emerging evidence of a possible association between mentor commitment and retention (Gettings \& Wilson, 2014), these findings suggest specific practices through which mentoring programs may contribute to mentor retention and potentially influence the duration and quality of youth mentoring relationships.

As predicted by the investment model (Rusbult, 1980) and consistent with previous youth mentoring research (Gettings \& Wilson, 2014), mentors' commitment to the mentoring relationship was positively associated with their satisfaction with the relationship and their investment, and negatively associated with their perception of available alternatives, such as being matched with another youth or not mentoring at all. As hypothesized, mentors' commitment also was associated with program practices, specifically their perceptions about how well the mentoring program had set expectations about the relationship prior to matching, how much time was devoted to pre-match training, and whether they felt they were matched with a youth based on their preferences. The association between expectation setting and commitment was mediated by satisfaction with the relationship, which is consistent with previous research showing that mentors who do not have expectations that align with their match can become dissatisfied, leading them to terminate the relationship (Spencer, 2007b; Spencer et al., 2017; Spencer et al., 2019). In addition, the association between the amount of time devoted to pre-match training and commitment was mediated by the mentor's investment in the relationship. Attending training is an investment in and of itself, but training may also help mentors to invest in other ways as well (Herrera et al., 2002). Finally, the association between matching based on the mentor's preferences and relationship commitment was mediated by available alternatives. Mentors who felt that the program took their preferences into consideration when matching them with a mentee were less likely to feel that they would be 
PROGRAM PRACTICES AND MENTOR COMMITMENT

better matched with another youth and therefore felt more committed to maintaining the relationship.

This study differs from most previous research on youth mentoring programs by including mentors from programs with a wide variety of structures, models, settings and sizes, and accounting for between-program differences using multilevel modeling. Individual mentoring studies tend to focus on a single program model or type, and over-represent large, national mentoring programs such as Big Brothers Big Sisters (e.g., Grossman \& Rhodes, 2002; Grossman \& Tierney, 1998; Herrera et al., 2011; Spencer, 2007a, 2007b; Spencer et al., 2017). Similarly, meta-analyses and reviews typically limit their scope to a specific model of mentoring such as one-on-one relationships (e.g., DuBois et al., 2002) or school-based matches (e.g., Wheeler et al., 2010). The findings of the current study suggest the applicability of the investment model beyond its previous application to one-on-one mentoring (Gettings \& Wilson, 2014) to other models of mentoring, such as team or group mentoring, and show the role of setting clear expectations, pre-match training, and matching based on preferences across program types. The variety of programs and mentoring relationships represented in this work supports its generalizability.

\section{Limitations and Future Research}

Several limitations of the current study suggest avenues for future research. This study relies on mentor reports of their perceptions of mentoring program practices, provided retrospectively. Mentors may not know what the mentoring program staff have done or may not have a point of reference to know how well procedures were followed. However, the relatively large intraclass correlations for programs practices in this study suggest consistency of practice implementation within a program, supporting the efficacy of relying on mentor reports of 
PROGRAM PRACTICES AND MENTOR COMMITMENT

program practices. Triangulating mentor reports with staff-reported information about the extent to which they followed program procedures with a given mentor would enhance the validity of future research. However, even with this additional information, mentors' perceptions of program practices may matter more to mentors' experiences, including relationship commitment, than what the program staff actually did. For example, the mentor's perception of fewer alternatives is more likely linked to the mentor's belief the match was made based on their preferences than to program staff thinking they made the match based on these preferences. Similarly, mentoring program staff may think they are setting clear expectations for mentors, but the messaging may not be received clearly by mentors or align with their actual experience. Additional research could explore the relative importance of mentor and staff reports of program procedures on mentor commitment.

Another potential measurement concern is that the retrospective mentor perceptions of pre-match program practices may have been influenced by their later experiences in the match (e.g., a frustrated mentor may look back and feel that the program did a poor job setting expectations). The use of cross-sectional data further limits the ability to infer causality. However, examining how perceptions of practices that occurred before the match began are associated with current commitment implies a temporal sequence consistent with a causal mechanism despite the limitations of cross-sectional data. Nevertheless, longitudinal data collected at multiple time points would increase the ability to draw causal conclusions regarding the influence of mentors' perceptions of pre-match program practices and the development of relationship commitment. Longitudinal research also would allow for observation of changes in the investment model variables over time (Rusbult et al., 1998).

\section{Implications for Practice}


PROGRAM PRACTICES AND MENTOR COMMITMENT

The results of this study suggest that mentors' perceptions of certain program practices have direct associations with mentor commitment as well as indirect associations mediated by relationship satisfaction, investment, and available alternatives. The findings suggest that programs attempting to increase mentor commitment should set clear expectations with mentors prior to the start of the match, provide more pre-match training, and match mentors and youth based on the mentor's preferences. All are recommended practices for mentoring programs (MENTOR, 2015), and these results highlight their importance across a wide range of program models and settings. 
PROGRAM PRACTICES AND MENTOR COMMITMENT

\section{References}

Deutsch, N. L., Reitz-Krueger, C. L., Henneberger, A. K., Futch Ehrlich, V. A., \& Lawrence, E. C. (2017). "It gave me way to solve my problems and ways to talk to people": Outcomes from a combined group and one-on-one mentoring program for early adolescent girls. Journal of Adolescent Research, 32(3), 291-322.

DuBois, D. L., Holloway, B. E., Valentine, J. C., \& Cooper, H. (2002). Effectiveness of mentoring programs for youth: A meta-analytic review. American Journal of Community Psychology, 30, 157-197.

DuBois, D. L., Portillo, N., Rhodes, J. E., Silverthorn, N., \& Valentine, J. C. (2011). How effective are mentoring programs for youth? A systematic assessment of the evidence. Psychological Science in the Public Interest, 12, 57-91.

Garson, G. D. (2014). Path Analysis (2014 Edition). Available from http://www.statisticalassociates.com/pathanalysis.htm

Gettings, P. E., \& Wilson, S. R. (2014). Examining commitment and relational maintenance in formal youth mentoring relationships. Journal of Social and Personal Relationships, 31(8), 1089-1115.

Grossman, J. B., \& Rhodes, J. E. (2002). The test of time: predictors and effects of duration in youth mentoring relationships. American Journal of Community Psychology, 30, 199219.

Grossman, J. B., \& Tierney, J. P. (1998). Does mentoring work? An impact study of the Big Brothers Big Sisters program. Evaluation Review, 22, 403-426.

Hancock, G. R., \& Mueller, R. O. (2004). Path analysis. In M. S. Lewis-Beck, A. Bryman, \& T. F. Liao (Eds.) The SAGE encyclopedia of social science research methods (Vol. 2, pp. 802-806). Thousand Oaks, CA: SAGE Publications, Inc. 
PROGRAM PRACTICES AND MENTOR COMMITMENT

Herrera, C., DuBois, D. L., \& Grossman, J. B. (2013). The Role of Risk: Mentoring Experiences and Outcomes for Youth with Varying Risk Profiles. New York, NY: A Public/Private Ventures project distributed by MDRC. Retrieved from http://www.mdrc.org/publication/role-risk

Herrera, C., Grossman, J. B., Kauh, T. J., Feldman, A. F., \& McMaken, J., \& Jucovy, L. (2007). Making a difference in schools: The Big Brothers Big Sisters school-based mentoring impact study. Philadelphia, PA: Public/Private Ventures. Retrieved from http://issuelab.org/home

Herrera, C., Grossman, J. B., Kauh, T. J., \& McMaken, J. (2011). Mentoring in Schools: An impact study of Big Brothers Big Sisters school-based mentoring. Child Development, 82, 346-361.

Herrera, C., Sipe, C., \& McClanahan, W. (2000). Mentoring school-age children: Relationship development in community-based and school-based programs. Philadelphia: Public/Private Ventures. Retrieved from http://www.vaservice.org/uploads/public/Resource_Library/ Guides_and_Manuals/Children_and_Youth/Mentoring/Mentoring_ School_Age_Children.pdf

Karcher, M. J. (2005). The effects of developmental mentoring and high school mentors' attendance on their younger mentees' self-esteem, social skills, and connectedness. Psychology in the Schools, 42(1), 65-77.

Keller, T. E. (2005a). A systemic model of the youth mentoring intervention. The Journal of Primary Prevention, 26(2), 169-188. 
PROGRAM PRACTICES AND MENTOR COMMITMENT

Keller, T. E. (2005b). The stages and development of mentoring relationships. In DuBois, D.L, \& Karcher, M. (Ed.), Handbook of Youth Mentoring (pp. 82-99). Thousand Oaks, CA: Sage Publications, Inc.

Keller, T. E., Spencer, R., Herrera, C., \& McBeath, B. (2019). Changing youth programs and settings: An experimental evaluation of the Quality Mentoring Systems initiative (Final Program Report). Portland, OR: Portland State University.

Kupersmidt, J. B., Stump, K. N., Stelter, R. L., \& Rhodes, J. E. (2017). Predictors of premature match closure in youth mentoring relationship. American Journal of Community Psychology, 59, 25-35.

Le, B., \& Agnew, C. R. (2003). Commitment and its theorized determinants: A meta-analysis of the Investment Model. Personal Relationships, 10, 37-57.

McClanahan, W. (1998). Relationships in a Career Mentoring Program: Lessons Learned from the Hospital Youth Mentoring Program. Philadelphia: Public/Private Ventures. Retrieved from http://issuelab.org/home

MENTOR (2015). Elements of Effective Practice for Mentoring (4th ed.). Boston, MA: Author.

Parra, G. R., DuBois, D. L., Neville, H. A., Pugh-Lilly, A. O., \& Povinelli, N. (2002). Mentoring relationships for youth: Investigation of a process-oriented model. Journal of Community Psychology, 30, 367-388.

Pryce, J., Kelly, M. S., \& Guidone, S. R. (2014). Mentor and youth matching. In D. L. DuBois \& M. J. Karcher (Eds.), Handbook of youth mentoring (2 ${ }^{\text {nd }}$ ed., pp. 427-438). Thousand Oaks, CA: SAGE Publications, Inc.

Rhodes, J. E. (2002). Stand by Me: The Risks and Rewards of Mentoring Today's Youth. Cambridge, MA: Harvard University Press. 
PROGRAM PRACTICES AND MENTOR COMMITMENT

Rhodes, J. E. (2005). A model of youth mentoring. In D. L. DuBois \& M. J. Karcher (Eds.), Handbook of youth mentoring (pp. 30-43). Thousand Oaks, CA: SAGE Publications, Inc.

Rhodes, J. E., Spencer, R., Keller, T. E., Liang, B., \& Noam, G. (2006). A model for the influence of mentoring relationship on youth development. Journal of Community Psychology, 34, 691-707.

Rusbult, C. E. (1980). Commitment and satisfaction in romantic associations: A test of the investment model. Journal of Experimental Social Psychology, 16, 172-186.

Rusbult, C. E., Martz, J. M., \& Agnew, C. R. (1998). The Investment Model Scale: Measuring commitment level, satisfaction level, quality of alternatives, and investment size. Personal Relationships, 5, 357-391.

Spencer, R. (2007a). "I just feel safe with him": Close and enduring male youth mentoring relationships. Psychology of Men and Masculinity, 8(3), 185-198.

Spencer, R. (2007b). 'It's not what I expected': A qualitative study of youth mentoring relationship failures. Journal of Adolescent Research, 22, 331-354.

Spencer, R., Basualdo-Delmonico, A., Walsh, J., \& Drew, A. L. (2017). Breaking up is hard to do: A qualitative interview study of how and why youth mentoring relationships end. Youth \& Society, 49(4), 438-460. doi: 10.1177/0044118X14535416.

Spencer, R., Gowdy, G., Drew, A. L., McCormack, M. J., \& Keller, T. E. (2019). It takes a village to break up a match: A systemic analysis of formal youth mentoring relationship endings. Child \& Youth Care Forum. Advanced online publication doi.org/10.1007/s10566-019-09520-w

Tran, P., Judge, M., \& Kashima, Y. (2019). Commitment in relationships: An updated metaanalysis of the Investment Model. Personal Relationships, 26, 158-180. 
PROGRAM PRACTICES AND MENTOR COMMITMENT

Wheeler, M. E., Keller, T. E., \& DuBois, D. L. (2010). Review of three recent randomized trials of school-based mentoring: Making sense of mixed findings. Social Policy Report, 23(3), $1-21$. 
PROGRAM PRACTICES AND MENTOR COMMITMENT

Table 1. Descriptive Characteristics of Mentoring Programs $(N=47)^{1}$

Program Characteristics $\% / M(S D)$

Organizational Structure

Embedded in Community Organization

Stand Alone Non-profit

29.8

Other

Provides Services Other Than Mentoring

59.6

Affiliated with a National Organization

Years Providing Mentoring Services

$11.5(12.5)$

Paid Staff Devoted to Mentoring Program

$2.6(3.8)$

Mentors Active During Last 12 Months

$107.6(197.2)$

${ }^{1}$ Agency-level surveys were not completed for 8 programs. 
PROGRAM PRACTICES AND MENTOR COMMITMENT

Table 2. Bivariate Correlations and Variable Means and Intraclass Correlations

\begin{tabular}{|c|c|c|c|c|c|c|c|}
\hline & 1 & 2 & 3 & 4 & 5 & 6 & 7 \\
\hline 1. Expectation setting & - & & & & & & \\
\hline 2. Pre-match training & $.260 * *$ & - & & & & & \\
\hline 3. Matched on preferences & $.589 * *$ & $.201 * *$ & - & & & & \\
\hline 4. Satisfaction & $.478 * *$ & $.171 * *$ & $.484 * *$ & - & & & \\
\hline 5. Available alternatives & $-.356 * *$ & -.071 & $-.499 * *$ & $-.656 * *$ & - & & \\
\hline 6. Investment & $.230 * *$ & $.162 * *$ & $.302 * *$ & $.603 * *$ & $-.423 * *$ & - & \\
\hline 7. Commitment & $.334 * *$ & $.150 * *$ & $.319 * *$ & $.594 * *$ & $-.517 * *$ & $.587 * *$ & - \\
\hline Respondents (N) & 501 & 476 & 492 & 536 & 535 & 536 & 537 \\
\hline Mean (S.D.) & $\begin{array}{l}4.31 \\
(.74)\end{array}$ & $\begin{array}{c}3.88 \\
(1.79)\end{array}$ & $\begin{array}{c}4.08 \\
(1.05)\end{array}$ & $\begin{array}{l}3.93 \\
(.65)\end{array}$ & $\begin{array}{l}2.04 \\
(.82)\end{array}$ & $\begin{array}{l}3.67 \\
(.64)\end{array}$ & $\begin{array}{l}4.31 \\
(.56)\end{array}$ \\
\hline ICC & .239 & .316 & .159 & .095 & .042 & .069 & .063 \\
\hline
\end{tabular}

$* p<.05, * * p<.01$

NOTE: Pre-match training was measured from 1 to 6 with a higher number indicating more training. All other variables were measured ranging from 1 to 5 where 1 indicates strong opposition and 5 indicates strong endorsement. 
PROGRAM PRACTICES AND MENTOR COMMITMENT

Table 3: Results of Preliminary Path Analyses of Model Components

\begin{tabular}{|c|c|c|c|c|c|}
\hline \multirow[b]{2}{*}{ Model } & \multicolumn{2}{|c|}{ Mediating variable } & \multicolumn{2}{|c|}{ Commitment } & \multirow[b]{2}{*}{ Model fit indices } \\
\hline & Path Coefficient & $\mathrm{R}^{2}$ & Path Coefficient & $\mathrm{R}^{2}$ & \\
\hline Investment Model & & & & & $\chi^{2}=38.88^{* *}$ \\
\hline$\overline{\text { Satisfaction }}$ & & & $.274 * * *$ & $.474 * * *$ & $\mathrm{CFI}=0.975$ \\
\hline Investment & & & $.331 * * *$ & & RMSEA $=0.049$ \\
\hline Alternatives & & & $-.201 * * *$ & & \\
\hline Expectation Setting & & & & & $\chi^{2}=11.49 * *$ \\
\hline Model A & & & & & $\mathrm{CFI}=0.868$ \\
\hline Expectation Setting & & & $.325^{* *}$ & .031 & RMSEA $=0.072$ \\
\hline Model B & & & & & $\chi^{2}=20.75 * *$ \\
\hline Expectation Setting (direct) & & & .056 & $.393 * * *$ & $\mathrm{CFI}=0.959$ \\
\hline Expectation Setting (mediated by Satisfaction) & $.476^{* * * *}$ & $.227 * * *$ & $.584 * * *$ & & RMSEA $=0.060$ \\
\hline Pre-match Training & & & & & $\chi^{2}=4.45^{*}$ \\
\hline Model A & & & & & CFI $=0.813$ \\
\hline Pre-match Training & & & $.123 * *$ & $.057 *$ & RMSEA $=0.079$ \\
\hline Model B & & & & & $\chi^{2}=30.02 * * *$ \\
\hline Pre-match Training (direct) & & & .058 & $.361 * * *$ & $\mathrm{CFI}=0.910$ \\
\hline Pre-match Training (mediated by Investment) & $.117 *$ & .024 & $.587 * * *$ & & RMSEA $=0.065$ \\
\hline Matching Based on Preferences & & & & & $\chi^{2}=9.14 *$ \\
\hline Model A & & & & & CFI $=0.846$ \\
\hline Matching Based on Preferences & & & $.304 * * *$ & $.093 * *$ & RMSEA $=0.080$ \\
\hline Model B & & & & & $\chi^{2}=10.24$ \\
\hline Matching Based on Preferences (direct) & & & .032 & $.308 * * *$ & CFI $=0.996$ \\
\hline $\begin{array}{l}\text { Matching Based on Preferences (mediated by } \\
\text { Alternatives) }\end{array}$ & $-.498 * * *$ & $.266^{* * * *}$ & $-.522 * * *$ & & RMSEA $=0.016$ \\
\hline
\end{tabular}


Figure 1. Hypothesized Path Model Using Perceived Program Practices to Predict Mentors' Relationship Commitment

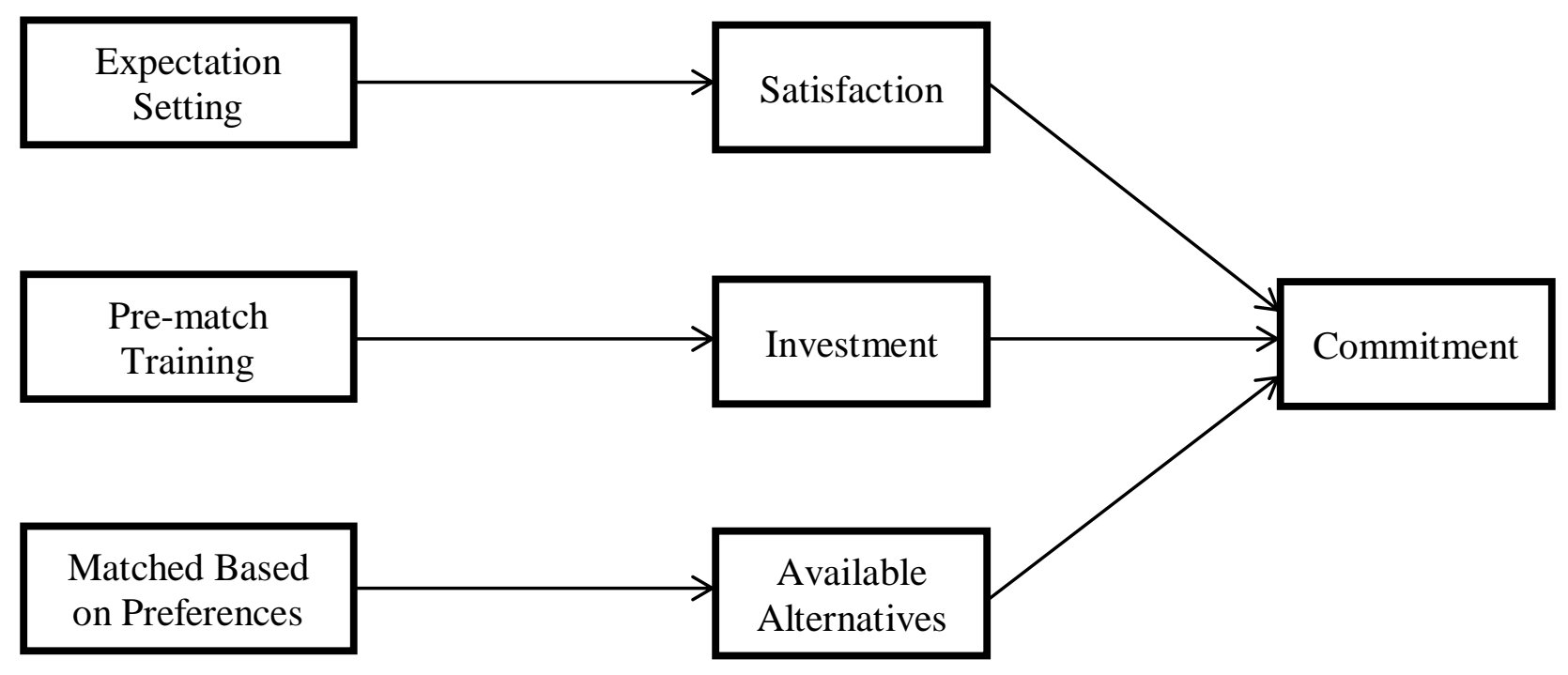


Figure 2. Final Path Model $(N=537)$

$$
\chi^{2}(53)=199.35, p<.001
$$

CFI $=0.883$, RMSEA $=0.072$
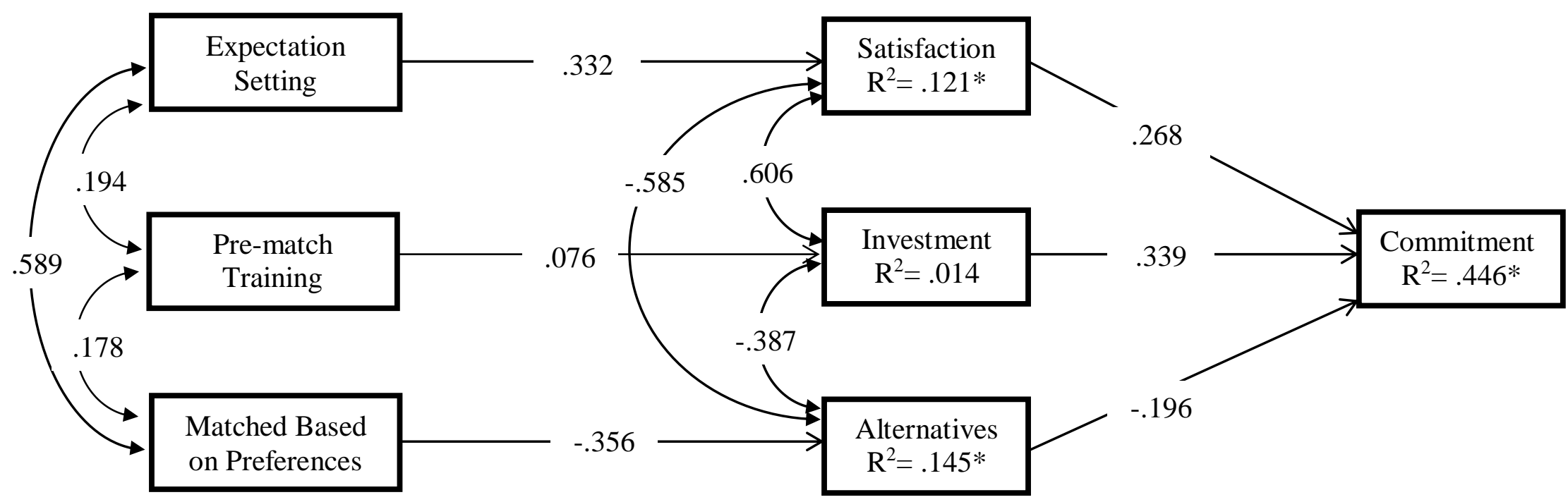

NOTE: Standardized path estimates are shown.

For all path estimates, $\mathrm{p}<.05$. * indicates an $\mathrm{R}^{2}$ with $\mathrm{p}<.05$.

The final model controls for demographic characteristics (mentor and youth age, and youth gender) and the mentoring setting (community-based or other). 